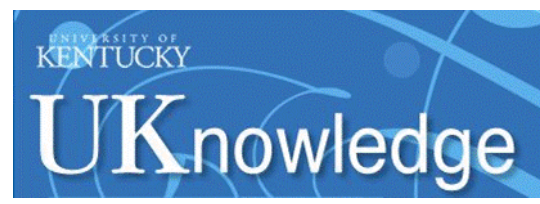

University of Kentucky

UKnowledge

$11-2011$

\title{
Linking impulsivity and inhibitory control using manual and oculomotor response inhibition tasks
}

\author{
Walter Roberts \\ University of Kentucky, walter.roberts@uky.edu \\ Mark T. Fillmore \\ University of Kentucky, fillmore@uky.edu \\ Richard Milich \\ University of Kentucky, richard.milich@uky.edu
}

Follow this and additional works at: https://uknowledge.uky.edu/psychology_facpub

Part of the Psychology Commons

Right click to open a feedback form in a new tab to let us know how this document benefits you.

\section{Repository Citation}

Roberts, Walter; Fillmore, Mark T.; and Milich, Richard, "Linking impulsivity and inhibitory control using manual and oculomotor response inhibition tasks" (2011). Psychology Faculty Publications. 122. https://uknowledge.uky.edu/psychology_facpub/122

This Article is brought to you for free and open access by the Psychology at UKnowledge. It has been accepted for inclusion in Psychology Faculty Publications by an authorized administrator of UKnowledge. For more information, please contact UKnowledge@lsv.uky.edu. 
Linking impulsivity and inhibitory control using manual and oculomotor response inhibition tasks

Digital Object Identifier (DOI)

http://dx.doi.org/10.1016/j.actpsy.2011.09.002

Notes/Citation Information

Roberts, W., Fillmore, M. T., \& Milich, R. (2011) Acta Psychologica, v. 138, no. 3, p. 419-428.

Copyright @ 2011 Elsevier B.V. All rights reserved.

This article is available at UKnowledge: https://uknowledge.uky.edu/psychology_facpub/122 


\title{
Linking impulsivity and inhibitory control using manual and oculomotor response inhibition tasks
}

\author{
Walter Roberts, Mark T. Fillmore *, Richard Milich \\ University of Kentucky, Department of Psychology, 115 Kastle Hall, Lexington, KY, 40506-0044, USA
}

\section{A R T I C L E I N F O}

\section{Article history:}

Received 25 April 2011

Received in revised form 6 September 2011

Accepted 12 September 2011

Available online 7 October 2011

\section{PsycInfo classification:}

2340

3120

3230

Keywords:

Impulsivity

Inhibitory control

Manual

Oculomotor

ADHD

\begin{abstract}
A B S T R A C T
Separate cognitive processes govern the inhibitory control of manual and oculomotor movements. Despite this fundamental distinction, little is known about how these inhibitory control processes relate to more complex domains of behavioral functioning. This study sought to determine how these inhibitory control mechanisms relate to broadly defined domains of impulsive behavior. Thirty adults with attention-deficit/ hyperactivity disorder (ADHD) and 28 comparison adults performed behavioral measures of inhibitory control and completed impulsivity inventories. Results suggest that oculomotor inhibitory control, but not manual inhibitory control, is related to specific domains of self-reported impulsivity. This finding was limited to the ADHD group; no significant relations between inhibitory control and impulsivity were found in comparison adults. These results highlight the heterogeneity of inhibitory control processes and their differential relations to different facets of impulsivity.
\end{abstract}

(c) 2011 Elsevier B.V. All rights reserved.

\section{Introduction}

Inhibitory control is a complex construct that can be broadly defined as the ability to prevent prepotent actions. It has long been a topic of interest in numerous areas of personality and psychopathology, including childhood behavior disorders (i.e., attention-deficit/hyperactivity disorder [ADHD], conduct disorder), personality disorders, and addiction (Nigg, 2000). Accordingly, investigators from various divisions of psychology have put forward methods of measuring inhibitory control. Personality researchers have measured impulsivity through self-report inventories, whereas researchers in the cognitive sciences have focused on measuring inhibitory control at the behavioral level. ${ }^{1}$ Bridging these two methods of assessment is the assumption that the impulsive personality type is driven, at least in part, by behavioral disinhibition. Both methods have proven effective in differentiating between disinhibited and comparison groups (Lawrence, Luty, Bogdan, Sahakian, \& Clark, 2009); however, there has generally been poor agreement

\footnotetext{
* Corresponding author. at: Department of Psychology, 15 Kaste Hall, Lexington, KY, 40506-0044, USA. Tel.: +1 859257 4728; fax: +1 8593231979.

E-mail address: fillmore@uky.edu (M.T. Fillmore).

${ }^{1}$ In the current study, constructs measured by self-report inventories are referred to as impulsivity, and those measured by behavioral tasks are referred to as inhibitory control processes. Delineating between inhibitory control and impulsivity according to measurement method deemphasizes the important overlap between these two constructs (see Nigg, 2000), but is done so here in the interest of clarity.
}

between these behavioral and self-report measures at the individual difference level. In the current study, we used a series of inhibitory control tasks to examine how these cognitive mechanisms relate to domains of impulsivity. Specifically, we examined how inhibitory control of oculomotor and manual responding related to facets of self-reported impulsivity. In addition, we examined whether these relations differed between a group characterized by disinhibition (i.e., adults with ADHD) and a group of nonimpaired adults.

\subsection{Inhibitory control}

Inhibitory control represents a loose collection of cognitive processes that are grouped together by virtue of a common function: to facilitate behavioral and cognitive control by suppressing nonproductive behaviors or cognitive processing. It is not a unitary construct; instead, numerous inhibitory control mechanisms have been identified, and there are important differences in the neural circuitry underlying these discrete processes (Alexander, Crutcher, \& DeLong, 1991; Aron et al., 2007; Goldstein et al., 2007; Mostofsky et al., 2003). Furthermore, inhibitory mechanisms can be separated by functional characteristics, such as the type of action controlled by the mechanism (e.g., inhibiting a behavior or thought) or the context in which the mechanism is evoked. For example, there is a recognized separation between inhibitory processes activated in delayed reward scenarios and those that govern inhibition when no extended temporal delay is present (Dick et al., 2010). Inhibitory mechanisms also may be 
classified by the degree to which they are subject to conscious control (i.e., automatic versus intentional; Marzi, 1999). A more basic distinction exists between inhibitory mechanisms that govern overt behaviors (i.e., response inhibition) and those that reduce cognitive load by suppressing task-irrelevant information (i.e., interference control; Nigg, 2000). These and other more nuanced distinctions have prompted the development of numerous behavioral tasks meant to assess the various processes contained under the rubric of inhibitory control. For example, interference control is typically assessed using the Stroop task, whereas a delay-discounting task might be used to measure ability to delay responding for increased reward (Macleod, 1991; Mitchell, 1999).

Of the cognitive processes included in the inhibitory control taxonomy, our understanding of response inhibition is the most advanced with regard to measurement. Prepotent response inhibition is understood as the ability to suppress a prepotent action or inhibit an already initiated response (Dick et al., 2010). Tasks designed to measure response inhibition typically require a participant to execute a behavioral response (e.g., press a button) upon the presentation of a go target and inhibit that response upon the presentation of an infrequently occurring no-go target or stop-signal (Logan, Cowan, \& Davis, 1984; Marczinski \& Fillmore, 2003). Thus, participants are required to suppress the tendency to execute a prepotent behavioral response. Such tasks (e.g., cued go/no-go task, stop-signal task) have provided a means of measuring individuals' ability to inhibit behavioral responses; these methods have been instrumental in advancing our understanding of this inhibitory control process.

\subsection{Manual and oculomotor inhibitory control are independent processes}

Most measures of response inhibition have assessed inhibitory control of manual responding (e.g., button press). The inhibitory control processes that govern response inhibition of other behavior, such as eye movements, are not as well studied. There is evidence, however, that oculomotor inhibitory control operates separately from manual inhibitory control, both anatomically (Aron, Robbins, \& Poldrack, 2004) and functionally (Nigg, 2000). For example, the frontal eye field area is involved in the inhibition of saccadic eye movements (Hanes, Patternson, \& Schall, 1998; Schall, Stuphorn, \& Brown, 2002) but not manual actions (Chevrier, Noseworthy, \& Schachar, 2007). Children with ADHD show larger impairments of oculomotor inhibitory control relative to manual inhibitory control (Adams, Milich, \& Fillmore, 2010). Logan and Irwin (2000) provided behavioral evidence for the independence of these systems: manual inhibitory control differed from oculomotor inhibitory control in simple activation time, and these inhibitory processes were differentially affected by task manipulations. Furthermore, unlike manual inhibitory control, oculomotor inhibitory control processes are closely associated with the allocation of attention (Godijn \& Theeuwes, 2003). The ability to effectively inhibit saccades towards to-be-ignored stimuli is likely important in the effective execution of goal-directed actions. Consistent with this notion, dysfunctional inhibitory control of eye movements is thought to contribute to symptoms of inattention and distractibility associated with ADHD (Adams, Roberts, Fillmore, \& Milich, 2011), and has been observed in other types of psychopathology (e.g., obsessive-compulsive disorder; Rosenberg et al., 1997).

Recognizing that oculomotor inhibitory control likely constitutes a separate inhibitory system from manual inhibitory control, researchers have developed tasks used to measure inhibitory control of eye movements (Logan \& Irwin, 2000). These tasks are similar in principle to their manual counterparts-participants are required to inhibit a prepotent behavioral tendency. The difference here is in the behavior to be inhibited: instead of stopping a hand movement, participants must countermand a saccadic eye movement. In these tasks (e.g., countermanding task, delayed ocular response task [DORT]), participants are presented with a stimulus that would under normal circumstances capture attention and elicit a saccadic eye movement towards the location of that stimulus (Everling \& Fischer, 1998; Hanes \& Carpenter, 1999). Instead, participants are instructed to consciously inhibit this reflexive saccade and maintain focus on a fixation point in accordance with this internal goal.

Oculomotor inhibitory control tasks have been instrumental in furthering our understanding of attentional processes, and more recently these tasks have been applied to the study of psychopathology. Dysfunction of oculomotor inhibitory control may disrupt other cognitive processes (e.g., selective attention; Houghton \& Tipper, 1994) and may play a role in the symptom profiles of numerous psychological and neurological disorders (Ross, Harris, Olincy, \& Radant, 2000). These findings provide preliminary empirical evidence that disruption of the basic cognitive processes captured by these tasks may result in maladaptive behavior. Considering the independence of oculomotor and manual inhibitory control, it is likely that impairments of each process would manifest as separate constellations of behavioral tendencies. Consistent with this notion, Weafer, Fillmore, and Milich (2011) demonstrated that manual and oculomotor inhibitory control differed in their relations with alcohol-use behaviors. These researchers reported that oculomotor inhibitory control uniquely predicted alcohol-use behavior in adults with ADHD, whereas the relation between manual inhibitory control and alcohol use did not differ across groups. This highlights the importance of recognizing a distinction between manual and oculomotor inhibitory control processes. Furthermore, considering that these relations differed between ADHD and comparison adults, there may be a benefit in examining how inhibitory control deficits manifest in special populations. Although encouraging, this research is preliminary and examined a relatively narrow domain of behavior (i.e., alcohol-use behavior). Many questions remain as to how separate inhibitory control processes differentially relate to more broadly defined areas of behavioral functioning, such as impulsivity (Dick et al., 2010).

\subsection{Inhibitory control and impulsivity}

In the personality literature, impulsivity refers to several different personality processes that lead to rash or unplanned acts (Dick et al., 2010). A shift towards a heterogeneous view of impulsivity has occurred in recent years. Whiteside and Lynam (2001) identified four personality traits associated with impulsive behaviors, including urgency (i.e., tendency to experience strong impulses under negative affect), (lack of) premeditation (i.e., tendency to act on the spur of the moment without regard to the consequences), (lack of) perseverance (i.e., difficulty with focusing on a task that may be boring or difficult), and sensation seeking (i.e., tendency to enjoy activities that are exciting or novel). Such multi-trait models of impulsivity recognize that a single impulsive behavior might be realized through multiple personality pathways. For example, a person may impulsively use drugs to alleviate negative affect (i.e., urgency) or because he or she is unable to foresee negative consequences associated with this behavior (i.e., [lack of] premeditation).

There is reason to expect agreement between behavioral measures of inhibitory control and trait impulsivity. For example, models of child temperament identify poor inhibitory control (i.e., effortful control; Rothbart \& Ahadi, 1994) as a pathway to impulsive personality (Nigg, 2000). Studies examining the relations between impulsivity inventories and behavioral measures of manual inhibitory control have typically reported poor agreement among measures, however (e.g., Lawrence et al., 2009; Lane, Cherek, Rhoades, Pietras, \& Tcheremissine, 2003; but see Logan, Schachar, \& Tannock, 1997). These inconsistent findings likely reflect methodological issues relating to the measurement of impulsivity. It is common practice to measure impulsivity using an omnibus self-report measure that does not differentiate between the facets of impulsivity, and instead provides a single score 
that aggregates across these variables (Nigg, 2000). Representing several constructs with a single score results in imprecise measurement with questionable validity (Smith \& Combs, 2010). Considering this, it is not surprising that relations between self-report and behavioral measures have been poor. Dick et al. (2010) recognized this issue and identified behavioral tasks and self-report measures that conceptually converge on underlying facets of impulsivity. For example, these authors proposed conceptual overlap between response inhibition and urgency, and hypothesize agreement between behavioral and self-report measures of manual inhibitory control and urgency, respectively.

\subsection{The current study}

Evidence for the independence between oculomotor and manual inhibitory processes raises questions as to how these inhibitory control processes relate to broadly defined domains of impulsive behavior. For example, perhaps oculomotor inhibitory control relates to individuals' ability to persevere in uninteresting tasks (i.e., [lack of] perseverance), whereas manual inhibitory control relates to individuals' tendency to act rashly when experiencing extreme moods (i.e., urgency; Dick et al., 2010). Alternatively, it may be that these inhibitory control processes contribute to identical facets of impulsivity, and only differ in the degree to which they relate to these domains.

In the current study, we sought to answer these questions by examining the relations of manual and oculomotor inhibitory control to several domains of self-reported impulsivity in adults with ADHD and healthy control adults. Specifically, we tested whether performance on oculomotor inhibitory control tasks differed from performance on manual inhibitory control tasks in their relations with self-reported impulsivity. A group of young adults with and without ADHD performed two behavioral measures of oculomotor inhibitory control, including a delayed ocular response task (DORT) and a visual stopping task, and two behavioral measures of manual inhibitory control, including a manual stopping task and a cued go/no-go task. The visual and manual stopping tasks were designed to differ only in the required response type: the visual stopping task required the participant to countermand a saccadic eye movement, whereas the manual stopping task required the inhibition of a manual response. Participants completed three well-validated impulsivity inventories: the Eysenck Impulsivity Questionnaire (Eysenck, Pearson, Easting, \& Allsopp, 1985), the Barratt Impulsivity Scale-11 (Patton, Stanford, \& Barratt, 1995), and the UPPS Impulsive Behavior Scale (Whiteside \& Lynam, 2001).

Two hypotheses were offered. First, we hypothesized that performance on the visual stopping task would be more closely related to self-reported impulsivity than performance on the manual stopping task. This prediction was based on evidence supporting the independence of manual and oculomotor inhibitory control systems. In addition, oculomotor inhibitory control has been reliably linked with impulsivity, whereas manual inhibitory control has been less consistent in demonstrating this relation (e.g., Jacob et al., 2010). Additionally, we expected that inhibitory control would relate to specific facets of the UPPS Impulsive Behavior Scale. We expected that oculomotor inhibitory control would relate to (lack of) premeditation and (lack of) perseverance, and manual inhibitory control would relate to urgency. Prior research has identified a relation between oculomotor inhibitory control and (lack of) premeditation (Jacob et al., 2010). The role of oculomotor inhibition in attentional control provides conceptual overlap with (lack of) perseverance. Urgency has been linked conceptually with prepotent response inhibition (Dick et al., 2010), and prior research has supported this notion (Gay, Rochat, Billieux, d'Acremont, \& Van der Linden, 2008). Demonstrating a link between behavioral measures of inhibitory control and a single subscale of the UPPS would provide evidence for the specificity of the UPPS factor structure.
Second, we hypothesized that oculomotor inhibitory control-as measured by the DORT-would relate more closely to impulsivity in the ADHD group relative to the control group. This prediction was based on prior work suggesting that DORT performance relates to behavioral functioning more strongly in adults with ADHD relative to control adults (Weafer et al., 2011).

\section{Method}

\subsection{Participants}

Participants included 30 individuals with ADHD (17 men and 13 women; $M$ age $=21.1$ years, $S D=1.7)$ and 28 individuals with no history of $A D H D$ ( 13 men and 14 women; $M$ age $=22.0$ years, $S D=1.7$ ). The sample was predominately Caucasian $(n=50)$, although it included participants who identified as Asian-American $(n=4)$, African-American $(n=3)$, and Latino $(n=1)$. Participants were recruited through advertisements (i.e., newspaper ads and posters) seeking adults for a study of neurological and motor functioning. Participation was limited to individuals who were between the ages of 19 and 30 and had no uncorrected vision problems. Individuals with a past or current severe psychiatric diagnosis (i.e., bipolar disorder, schizophrenia) or pervasive developmental disorder, as determined through self-report and medical records, were not invited to participate. Demographic information is shown in Table 1.

To ensure that members of the ADHD group were actively experiencing ADHD symptoms, only those who were currently prescribed medication for ADHD were invited to participate. Members of the ADHD group reported several different prescriptions, including mixed-amphetamine salts $(n=23)$, methylphenidate $(n=5)$, and dextroamphetamine $(n=2)$. Participants in the ADHD group were asked to provide informed consent for the access of medical records for the purpose of confirming the diagnosis. The ADHD group included only individuals whose diagnosis could be confirmed through medical records. Participants were asked to discontinue the use of their medication for $24 \mathrm{~h}$ prior to the study to ensure that they were unmedicated during the testing sessions.

Table 1

Demographic and diagnostic information by group.

\begin{tabular}{|c|c|c|c|c|c|}
\hline & \multicolumn{4}{|l|}{ Group } & \multirow[t]{3}{*}{$t$} \\
\hline & \multicolumn{2}{|c|}{ Control $(n=28)$} & \multicolumn{2}{|c|}{$\operatorname{ADHD}(n=30)$} & \\
\hline & Mean & SD & Mean & SD & \\
\hline \multicolumn{6}{|l|}{ Demographic } \\
\hline Age & 22.1 & 1.7 & 21.1 & 1.7 & $2.2^{*}$ \\
\hline Gender (\% male) & 56.7 & & 46.2 & & \\
\hline Education & 15.3 & 1.2 & 15.1 & 1.0 & 0.7 \\
\hline IQ: Verbal & 107.0 & 6.9 & 103.2 & 10.8 & 1.6 \\
\hline IQ: Nonverbal & 111.0 & 8.6 & 105.6 & 9.8 & $2.2^{*}$ \\
\hline IQ: Composite & 109.9 & 6.9 & 104.9 & 10.1 & $2.3^{*}$ \\
\hline \multicolumn{6}{|l|}{ Diagnostic } \\
\hline \multicolumn{6}{|l|}{ CAARS } \\
\hline DSM-IA & $51.0(3)$ & 10.9 & $75.9(24)$ & 11.5 & $8.3^{* * * *}$ \\
\hline DSM-HI & $46.3(1)$ & 9.5 & $64.8(16)$ & 14.8 & $5.5^{* * *}$ \\
\hline DSM-Tot & $48.9(3)$ & 11.2 & $73.7(23)$ & 11.8 & $5.6^{* * *}$ \\
\hline DSM & $1.6(3)$ & 2.0 & $6.8(27)$ & 2.1 & $9.7^{* * *}$ \\
\hline AASRS & $8.1(9)$ & 5.5 & $21.4(29)$ & 5.8 & $8.8^{* * * *}$ \\
\hline
\end{tabular}

Note. Group contrasts were tested by independent sample $t$ tests. For all comparisons, $d f=56$. Age is reported in years. Education refers to years of education completed. IQ: Verbal, IQ: Nonverbal, and IQ: Composite refers to respective scaled scores of the Kaufman Brief Intelligence Test. CAARS scores are T-scores; DSM-IA is DSM-IV Inattentive Symptoms, DSM-HI is DSM-IV Hyperactive-Impulsive Symptoms, DSMTot is DSM-IV ADHD Symptoms Total, and Index is ADHD Index. DSM refers to symptom count on the ADHD symptoms checklist. AASRS refers to total score on the ADD/H Adolescent Self-Report Scale-Short Form. The numbers in parentheses indicate the number of participants in each group scoring above the diagnostic cutoff on each measure.

* $p<.05$.

*** $p<.001$. 
In addition to medical records, ADHD diagnosis was confirmed by meeting symptom-based criteria on at least two of three ADHD scales, including the $\mathrm{ADD} / \mathrm{H}$ Adolescent Self-Report Scale-Short Form (AASRS; Robin \& Vandermay, 1996), the Conners Adult ADHD Rating Scale-Long Form (CAARS-S: L; Conners, Erhardt, \& Sparrow, 1999), and an ADHD Symptom Checklist of 12 ADHD symptoms that serve as diagnostic criteria according to the Diagnostic and Statistical Manual of Mental Disorders (4th ed. [DSM-IV]; American Psychiatric Association, 1994). All available information pertaining to diagnostic status (i.e., symptom ratings scales, available clinical records) was reviewed by a licensed clinical psychologist with over 30 years of experience in diagnosing ADHD. This method of diagnosis confirmation has been successfully used by this research group in other studies (e.g., Roberts, Fillmore, \& Milich, 2011; Weafer, Fillmore, \& Milich, 2009).

The AASRS-Short Form assessed symptoms experienced within the last month; this provided confirmation that participants were currently experiencing ADHD symptoms. The utilized cutoff score for this scale was the recommended diagnostic criterion of 10 or higher. The current study used the DSM-IV total symptoms subscale on the CAARS-S: L, which is based on well-established DSM-IV criteria of ADHD. This scale assessed the presence of ADHD symptoms throughout adulthood. For the current study, the diagnostic criteria for the CAARS-S: L was a T score greater than 65 on the DSM-IV total symptoms scale. Both scales have been shown to have sufficient specificity and sensitivity in identifying individuals with ADHD (Erhardt, Epstein, Conners, Parker, \& Sitarenios, 1999; Robin \& Vandermay, 1996). The ADHD Symptom Checklist was created using DSM-IV items that loaded highly on the ADHD symptoms factor on the Young ADHD Questionnaire-Self-Report (Young, 2004). The scale emphasized adult ADHD symptoms and included six symptoms of inattention and six symptoms of hyperactivity. The respondent rated the frequency of symptom occurrence as not at all, sometimes, often, and very often. Each item that the respondent rated as occurring often or very often was counted towards the symptom total, and a symptom total of four or more was used as diagnostic criteria.

All participants were screened using health questionnaires and a medical history interview. These measures assessed participants' current or past medical disorders, including serious physical disease, impaired cardiovascular functioning, chronic obstructive pulmonary disease, seizure, head trauma, CNS tumors, or histories of psychiatric disorder. Participants in the comparison group reported past or current diagnoses of depression and/or anxiety $(n=4)$, bipolar disorder $(n=1)$ and alcohol abuse $(n=1)$. Those in the ADHD group reported past or current diagnoses of depression and/or anxiety $(n=5)$, alcohol abuse $(n=2)$, and learning disability $(n=1)$.

\subsection{Behavioral inhibitory control tasks}

\subsubsection{Cued go/no-go task}

The cued go/no-go task measured inhibitory control of manual responding. This task has been utilized in prior studies to demonstrate the effects of drugs on inhibitory control (e.g., Fillmore, Rush, \& Hays, 2006; Marczinski \& Fillmore, 2003). Each trial consisted of a set sequence of events. First, a fixation cue $(+)$ was presented for $800 \mathrm{~ms}$. Second, a blank white screen was presented for $500 \mathrm{~ms}$. Third, a cue was displayed for $100,200,300,400$, or $500 \mathrm{~ms}$. The cue was presented either horizontally or vertically. Fourth, a green (go) or blue (no-go) target was presented that terminated either when the participant responded or after $1000 \mathrm{~ms}$. Participants were instructed to press the forward slash (/) key on the keyboard if the cue turned green (i.e., go target) and to suppress the response if the cue turned blue (i.e., no-go target). Fifth, response time was displayed after each trial to encourage quick responding. Lastly, a blank screen was presented for $700 \mathrm{~ms}$ prior to the beginning of the next trial.

The orientation of the cue (horizontal or vertical) signaled the probability that a go or no-go target will be displayed. Cues presented vertically preceded the go target on $80 \%$ of the trials and preceded the no-go target on $20 \%$ of the trials. Conversely, cues presented horizontally preceded the no-go target on $80 \%$ of the trials and preceded the go target on $20 \%$ of the trials. Participants associated the vertical cue with the go target, so the presentation of a vertical cue primed a participant to respond.

A test consisted of 250 trials that presented the four possible cuetarget combinations. An equal number of vertical (125) and horizontal (125) cues were presented before an equal number of go (125) and no-go (125) target stimuli. Each cue-target combination was presented at each of the five SOAs, and an equal number of SOAs separated each cue-target combination. The presentation of cue-target combinations and SOA was random. The task required approximately 15 min to complete.

The primary dependent variable from this task was the proportion of commission errors on go cue/no-go target trials ( $\mathrm{p}$-inhibitory failures), which reflects participants' ability to inhibit a manual action when they are cued to respond. Additional criterion variables included the proportion of commission errors during no-go cue/no-go target trials and RT during no-go cue/go target and go cue/go-target trials.

\subsubsection{Manual stopping task (Logan et al., 1984)}

The manual stopping task was used as a measure of manual response inhibition. This task required participants to press a button when a stimulus (go signal) appears on the screen, but to withhold responding when a stop signal tone was presented. The go signalswhite circles measuring $8 \mathrm{~mm}$ in diameter-were presented individually. Each trial began with a $1000 \mathrm{~ms}$ presentation of a plus sign $(+)$ in the middle of the computer display. This served both as a location for the participants to fixate their attention and as an indication that a trial was about to begin. As soon as the plus sign disappeared, a circle appeared in one of four positions: far right (12 cm from center), middle right $(6.5 \mathrm{~cm}$ from center) far left $(12 \mathrm{~cm}$ from center), and middle left $(6.5 \mathrm{~cm}$ from center). Participants were required to press the forward slash key (/) on a standard keyboard as soon as they detected a circle on the right or the period key (.) if the circle was on the left, using their middle and index fingers, respectively. The circle appeared on the screen for $1000 \mathrm{~ms}$. A blank screen was then presented for $1500 \mathrm{~ms}$ before the start of the next trial. The complete task involved 128 trials, with each of the four stimulus positions presented 32 times. A stop-signal tone occurred on 32 trials (i.e., $25 \%$ of the time), equally distributed among circle positions. The stop-signal was a $900 \mathrm{~Hz}$ tone presented for $500 \mathrm{~ms}$ at a comfortable listening level. Participants were instructed to inhibit their response when the stop-signal occurred. Stop signals were presented eight times at each of four stimulus onset asynchronies $(50,150,250$, and $350 \mathrm{~ms}$ ) with respect to the onset of the circle presentation. The order of circle locations, stop-signal presentation, and delays were random. The test required approximately 8 min to complete.

\subsubsection{Visual stopping task}

The visual stopping task-also known in the literature as the countermanding task-was used as a measure of oculomotor inhibitory control. This task was similar to the manual stopping task, but rather than press a button, participants moved their eyes from a fixation point to the location of the go signal when it was presented. Participants were instructed not to look at the go signal when a stop-signal was presented. With the exception of response modality, all other task characteristics were the same as those described for the manual stopping task.

The primary criterion variable for both stopping tasks was stopsignal reaction time (SSRT), which represents an estimate of the time required to activate an inhibitory response. SSRT was calculated according to Logan (1994). Additional criterion variables for both stopping tasks include reaction time during go trials (RTgo) and 
omission errors. Choice-response errors are only reported for the manual stopping task, because participants did not make choiceresponse errors on the visual stopping task. Anticipatory responses that took place within $100 \mathrm{~ms}$ of the stimulus presentation were excluded as were responses committed more than $1000 \mathrm{~ms}$ following the go target presentation.

\subsubsection{Delayed ocular response task (DORT)}

This task assessed oculomotor inhibitory control by measuring a participant's ability to intentionally inhibit a reflexive saccade toward the sudden appearance of a visual stimulus on a computer screen. Participants were seated in a darkened room and instructed to maintain focus on a fixation point. While participants were focused on the fixation point, a bright target stimulus was presented in the periphery. The sudden appearance of such a stimulus would normally elicit a reflexive saccade towards the stimulus (Peterson, Kramer, \& Irwin, 2004). However, participants are instructed to "delay" looking at this stimulus, and instead maintain their gaze on the fixation point until it disappears. Thus, this task required the intentional inhibition of a reflexive saccade.

A trial began with the presentation of a white fixation point $(+)$ against a black background. Participants were instructed to fixate on this point. After $1500 \mathrm{~ms}$, the target stimulus (a white circle) briefly appeared for $100 \mathrm{~ms}$ to the left or right of the fixation point. The fixation point then remained on the screen for a random "wait" interval (800, 1000 , and $1200 \mathrm{~ms}$ ), during which participants were to withhold any saccade to the target. Following the wait interval, the central fixation point disappeared and the display was blank for $1000 \mathrm{~ms}$. Participants were told to execute a saccade to the location of the target stimulus as quickly as possibly upon the disappearance of the fixation point.

The task consisted of 96 trials and required 7 min to complete. Fixation points and targets were presented in five locations that were separated from each other by $4.1^{\circ}$ of visual angle. These positions were distributed horizontally across the center of the screen, resulting in four possible visual angles between the fixation point and target $\left(4.1^{\circ}, 8.2^{\circ}, 12.3^{\circ}\right.$, and $\left.16.4^{\circ}\right)$. Each trial began with the presentation of the fixation point at the target location of the preceding trial. Each of the four angular distances and the direction of the saccade required between the fixation point and target locations were presented on an equal number of trials during a test, such that 24 trials were presented at each angle with 12 of these going in each direction. The three different wait intervals each occurred in 32 trials. Target locations and wait intervals were presented in a random and unpredictable sequence.

The criterion variable of interest was the number of trials in which the participant executed a saccade towards the distracter location prior to the offset of the fixation point (i.e., premature saccades). Additional criterion variables from the DORT included saccadic RT and saccadic accuracy. Saccadic RT was defined as the time elapsed between the disappearance of the fixation point and the completion of a saccade towards the target region. Saccadic accuracy was defined as the angular discrepancy between the target position and the landing point of the saccade.

Eye movements during both oculomotor inhibitory control tasks were recorded using a Model 504 Eye Tracking System (Applied Science Laboratory, Boston, MA, USA), which sampled eye location at $60 \mathrm{~Hz}$ and recorded $\mathrm{X} / \mathrm{Y}$ coordinates. These coordinates were used to define fixations and saccades. Calculations of saccade distance and duration were done using fixation onset and offset times. Onsets of fixations were defined as periods of at least $100 \mathrm{~ms}$ in which the line of gaze had a standard deviation of less than $0.5^{\circ}$ of visual angle. Offsets of fixation were determined by periods of at least $50 \mathrm{~ms}$ in which the gaze position was at least $1^{\circ}$ of visual angle away from the initial fixation position. All sampled eye locations between the beginning and end of a fixation were averaged to produce a final fixation position. An inhibitory failure was defined as an eye movement covering at least half of the distance to the target location that occurred when the participant was instructed to withhold eye movements (i.e., prior to fixation offset on the DORT, during a stopsignal trial on the visual stopping task). To stabilize head movements participants' chins were placed in a chin rest at $73.6 \mathrm{~cm}$ from the computer display.

\subsection{Impulsivity measures}

\subsubsection{Barrett impulsiveness scale (BIS; Patton et al., 1995)}

This 30-item questionnaire measured impulsiveness through items such as "I act on impulse" and "I consider myself always careful". Participants indicated how frequently each statement applies to them on a 4-point Likert scale (never, occasionally, often, and almost always). Possible score totals ranged from 30 to 120 , with higher scores indicating greater total levels of impulsiveness. There are six first-order factors (i.e., attentional, cognitive complexity, cognitive instability, motor, perseverance, and self-control) that load onto three higher order factors (i.e., attentional impulsiveness [attention + cognitive instability], motor impulsiveness [motor + perseverance], and nonplanning impulsiveness [cognitive complexity + self-control]). For the current study, only the three higher order factors and total score were considered.

2.3.2. UPPS impulsive behavior scale (UPPS; Whiteside E Lynam, 2001)

The 45-item UPPS measured four personality traits associated with impulsive behavior, including urgency, (lack of) premeditation, (lack of) perseverance, and sensation seeking. Participants indicated to what degree each statement applies to them on a 4-point Likert scale.

\subsubsection{I.7 impulsiveness questionnaire (I.7; Eysenck et al., 1985)}

This questionnaire elicited yes or no responses from participants on items such as "Are you an impulsive person?" and "Do you mostly speak before thinking things out?" Participants in the current study completed the 17-item narrow impulsiveness subscale, which measures the tendency to act spontaneously without forethought or the consideration of consequences. This inventory is closely related to the (lack of) premeditation subscale of the UPPS.

\subsection{Procedure}

This study took place in a laboratory setting in the university's Department of Psychology. These tasks were administered as part of a larger testing battery that included other measures of cognitive functioning. Participants first attended an individual familiarization session in which they became acquainted with the eye tracking tasks and provided background information. After providing informed consent, participants were interviewed and completed questionnaires concerning their health status, drug and alcohol use, impulsivity, and demographic characteristics. IQ was assessed using the Kaufman Brief Intelligence Scale (K-BIT; Kaufman \& Kaufman, 1990). Participants in the ADHD group provided a signed release of their medical records and were interviewed regarding any medications currently prescribed for the disorder. All participants completed the ADHD scales. Participants were then trained on behavioral tasks to ensure that they understood the procedures. A testing session was then scheduled; this session was separated from the familiarization session by a minimum of $24 \mathrm{~h}$.

The testing session began with the participant completing preliminary questionnaires (e.g., verification that participants had not taken any medication). Upon completion of these questionnaires, participants completed the behavioral tasks in a fixed order. To avoid fatigue effects, participants were allowed breaks as needed between tasks. After the testing session concluded, the participants were debriefed and compensated approximately $\$ 50$ per session. 


\section{Results}

\subsection{Covariate and outlier analyses}

A chi-square analysis found that gender make-up was independent of group, $\chi^{2}(1, n=58)=0.61, p=.436$. Moreover, no significant gender differences were found on behavioral or self-report measures ( $p$ 's $>.08$ ). As seen in Table 1, groups differed significantly in age $(d=0.58)$ and IQ $(d=0.60)$. We examined the correlations between demographic variables (i.e., age, gender, and IQ) and behavioral and self-report measures to identify potential confounding variables. Although age correlated significantly with several measures of impulsivity (i.e., BIS-11 Total Score, BIS-11 Attention Impulsivity, UPPS: Urgency, Eysenck), its inclusion as a covariate did not significantly affect our results. Similarly, although IQ was correlated with BIS-11 Total Score and BIS-11 Nonplanning Impulsiveness, the inclusion of IQ as a covariate in analyses involving these variables did not change the results. Thus, the analyses are presented without the inclusion of these covariates. Two members of the ADHD group were identified as outliers on the visual stopping task because of extremely slow SSRTs and high leverage values (SSRT $=642.5 \mathrm{~ms}, 643 \mathrm{~ms}$ ). Subsequent analyses with visual SSRT do not include data from these participants.

\subsection{Between group comparisons}

Group comparisons on all self-report and behavioral measures are presented in Tables 2 and 3, respectively, and these data confirm the expected group differences in inhibitory control and impulsivity. The ADHD group committed significantly more premature saccades on the DORT and had a significantly slower SSRT on both the visual and manual stopping tasks relative to the controls. Groups were similar in the proportion of inhibitory failures committed during go-cue trials of the cued go/no-go task; however, there were significant group differences in the proportion of inhibitory failures committed during no-go cue trials and RT in both go and no-go cue trials. The ADHD group reported significantly higher levels of impulsivity than the control group on all self-report measures with the exception of the UPPS: Sensation Seeking. In general, these findings confirm the expected group differences in both impulsivity and inhibitory control.

A 2 (ADHD vs. control) $\times 2$ (visual SSRT vs. manual SSRT) mixeddesign analysis of variance was conducted to determine whether the ADHD group showed more inhibitory control impairment in the

Table 2

Between group comparisons of self-reported impulsivity.

\begin{tabular}{|c|c|c|c|c|c|c|}
\hline & \multicolumn{4}{|l|}{ Group } & \multirow[t]{3}{*}{$t$} & \multirow[t]{3}{*}{$d$} \\
\hline & \multicolumn{2}{|c|}{$\begin{array}{l}\text { Control } \\
(n=28)\end{array}$} & \multicolumn{2}{|c|}{$\begin{array}{l}\text { ADHD } \\
(n=30)\end{array}$} & & \\
\hline & Mean & SD & Mean & SD & & \\
\hline \multicolumn{7}{|l|}{ Self-report } \\
\hline 17 & 5.3 & 3.7 & 10.1 & 4.3 & $4.55^{* * *}$ & 1.22 \\
\hline BIS: Total & 52.6 & 8.4 & 68.5 & 9.9 & $6.58^{* * *}$ & 1.76 \\
\hline BIS: Attention & 12.9 & 3.1 & 18.7 & 3.0 & $7.24^{* * *}$ & 1.93 \\
\hline BIS: Motor & 20.2 & 3.2 & 25.1 & 3.8 & $5.26^{* * * *}$ & 1.41 \\
\hline BIS: NP & 19.5 & 4.4 & 24.7 & 4.9 & $4.21^{\text {*** }}$ & 1.13 \\
\hline UPPS: Premed & 2.0 & 0.5 & 2.5 & 0.6 & $3.16^{* *}$ & 0.84 \\
\hline UPPS: Urge & 2.1 & 0.5 & 2.6 & 0.6 & $3.26^{* *}$ & 0.87 \\
\hline UPPS: SS & 2.8 & 0.7 & 3.0 & 0.7 & 0.96 & 0.26 \\
\hline UPPS: Persev & 1.9 & 0.5 & 2.6 & 0.4 & $5.31^{\text {*** }}$ & 1.42 \\
\hline
\end{tabular}

Note. BIS: Total refers to total score on the BIS. BIS: Attention refers to the attentional impulsiveness subscale on the BIS. BIS: Behavior refers to the motor impulsiveness subscale on the BIS. BIS: NP refers to the non-planning impulsiveness subscale on the BIS. UPPS: Premed refers to the (lack of) premeditation subscale on the UPPS. UPPS: Urge refers to the urgency subscale on the UPPS. UPPS: SS refers to the sensation seeking subscale on the UPPS. UPPS: Persev refers to the (lack of) perseverance subscale on the UPPS.

** $p<.01$.
Table 3

Between group comparisons of inhibitory control task performance.

\begin{tabular}{|c|c|c|c|c|c|c|}
\hline & \multicolumn{4}{|l|}{ Group } & \multirow[t]{3}{*}{$t$} & \multirow[t]{3}{*}{$d$} \\
\hline & \multicolumn{2}{|c|}{$\begin{array}{l}\text { Control } \\
(n=28)\end{array}$} & \multicolumn{2}{|c|}{$\begin{array}{l}\text { ADHD } \\
(n=30) \\
\end{array}$} & & \\
\hline & Mean & SD & Mean & SD & & \\
\hline \multicolumn{7}{|c|}{ Delayed ocular response task } \\
\hline Premature saccades & 9.3 & 6.7 & 21.6 & 13.9 & $4.25^{* * *}$ & 1.14 \\
\hline Saccadic RT & 417.2 & 72.0 & 434.9 & 85.1 & 0.86 & 0.23 \\
\hline Saccadic accuracy & 1.6 & 0.4 & 1.7 & 0.6 & 0.61 & 0.16 \\
\hline \multicolumn{7}{|l|}{ Visual stopping task } \\
\hline SSRT & 273.8 & 66.0 & 365.8 & 106.8 & $3.87^{* * *}$ & 1.05 \\
\hline RTgo & 355.6 & 63.7 & 349.7 & 50.2 & 0.38 & 0.10 \\
\hline Omission errors & 3.6 & 3.3 & 4.9 & 4.9 & 1.21 & 0.33 \\
\hline \multicolumn{7}{|l|}{ Manual stopping task } \\
\hline SSRT & 228.3 & 50.2 & 267.4 & 68.1 & $2.47^{*}$ & 0.66 \\
\hline RTgo & 400.0 & 59.4 & 451.7 & 78.7 & $2.83^{* *}$ & 0.76 \\
\hline Omission errors & 0.7 & 1.0 & 3.1 & 4.4 & $2.93^{* *}$ & 0.78 \\
\hline Choice response errors & 0.6 & 0.9 & 1.0 & 1.8 & 1.04 & 0.28 \\
\hline \multicolumn{7}{|l|}{ Cued go/no-go task } \\
\hline Go cue: P-fail & 0.05 & 0.08 & 0.06 & 0.06 & 0.58 & 0.16 \\
\hline No-go cue: P-fail & 0.02 & 0.03 & 0.05 & 0.05 & $2.47^{*}$ & 0.66 \\
\hline Go cue: RT & 284.2 & 24.8 & 304.2 & 32.4 & $2.65^{*}$ & 0.71 \\
\hline No-go cue: RT & 299.1 & 20.6 & 315.6 & 35.1 & $2.21^{*}$ & 0.59 \\
\hline
\end{tabular}

SSRT refers to stop-signal reaction time (ms). RTgo refers to reaction time to go trials on the manual and visual stopping tasks. For variables in the visual stopping task, $n=28$ in the ADHD group.

$$
\begin{array}{rl}
* & p<.05 \\
* * & p<.01 \\
* * * & p<.001 .
\end{array}
$$

visual, relative to the manual, response modality. There was a significant main effect of group, $F(1,54)=14.0, p<.001, d=1.02$, and response condition, $F(1,54)=51.5, p<.001, d=1.95$, owing to slower SSRT in the ADHD group, and a slower visual SSRT in both groups. Moreover, there was a significant group $\times$ response type interaction, $F(1,54)=6.7, p=.013, d=0.70$. As seen in Fig. 1 , this interaction reflects a larger group difference on the visual stopping task relative to the manual stopping task.

\subsection{Individual difference analyses}

Having confirmed the expected group differences in impulsivity and inhibitory control, the next step was to examine the relations between measures at the level of individual differences. The pattern of correlations between inhibitory control and impulsivity are presented in Table 4. In general, the findings suggest that the oculomotor inhibitory control tasks are more closely related to self-reported impulsivity;

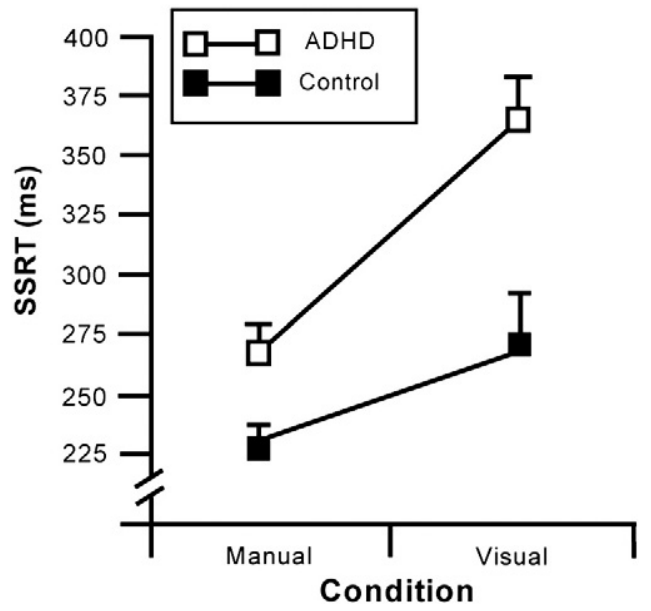

Fig. 1. Mean stop-signal reaction time $(+\mathrm{SE})$ of the ADHD and comparison groups on the manual and visual stopping task. 
these findings were unique to the ADHD group. Additional analyses were conducted to more specifically test our hypotheses.

Recall our first hypothesis that SSRT on the visual stopping task would be more predictive of self-reported impulsivity relative to SSRT on the manual stopping task. This hypothesis was tested using a series of multiple regression analyses. In these analyses, visual SSRT, manual SSRT, and group assignment were regressed onto impulsivity scores; the goal of these analyses was to determine whether visual SSRT accounted for incremental variance over manual SSRT. When entered simultaneously into a MLR model alongside manual SSRT and group assignment, visual SSRT accounted for incremental variance in the following self-report measures: I7, $\beta=.37, t(52)=2.4, p=.019, r_{\text {semipartial }}=.27$; BIS-11 Total Score, $\beta=.39, t(52)=3.2, p=.002, r_{\text {semipartial }}=.29$; BIS-11 Attention Impulsiveness, $\beta=.38, t(52)=3.3, p=.002, r_{\text {semipartial }}=.28$; BIS- 11 Motor Impulsiveness, $\beta=.41, t(52)=3.0, p=.004, r_{\text {semipartial }}=.30$; UPPS: Urgency, $\beta=.30, t(52)=1.8, p=.079, r_{\text {semipartial }}=.22$; and UPPS: Sensation Seeking, $\beta=.33, t(52)=1.8, p=.073, r_{\text {semipartial }}=.24$. SSRT on the manual stopping task was not predictive in any of these regression models. This finding supports our prediction that oculomotor inhibitory control is more closely related to impulsivity than manual inhibitory control.

The second hypothesis that the relation between premature saccades on the DORT and self-reported impulsivity would be stronger in the ADHD group was tested using a series of hierarchical regression analyses. Each model was completed as follows: group status was entered as the predictor in the first step, number of premature saccades was entered in the second step, and a group $\times$ premature saccades interaction term was entered in the final step. As seen in Table 5 , the group $\times$ premature saccades interaction term accounted for incremental variance in scores on the I7 and UPPS: Premeditation. These significant interactions provide support for our hypothesis. Specifically, the number of premature saccades was predictive of self-reported impulsivity only in the ADHD group. Within group correlations presented in Table 4 confirm that premature saccades predicted scores on the I7 and UPPS: Premeditation in the ADHD group ( $r s=.72, .64$, respectively) but not the control group ( $r \mathrm{~s}=-.09,-.05$, respectively).

\section{Discussion}

This study examined the relation between manual and oculomotor inhibitory control and domains of impulsivity in adults with and
Table 5

Hierarchical regressions of premature saccades on DORT on self-reported impulsivity.

\begin{tabular}{|c|c|c|c|c|c|c|}
\hline Measure & & & $d f$ & $\beta$ & $S E \beta$ & $\Delta R^{2}$ \\
\hline I7 & $\begin{array}{l}\text { Step } 1 \\
\text { Step } 2 \\
\text { Step } 3\end{array}$ & $\begin{array}{l}\text { Group } \\
\text { Premature saccades } \\
\text { Group* } \\
\text { Premature saccades }\end{array}$ & $\begin{array}{l}1,56 \\
2,55 \\
3,54\end{array}$ & $\begin{array}{l}0.52 \\
0.47 \\
1.54\end{array}$ & $\begin{array}{l}0.11 \\
0.12 \\
0.61\end{array}$ & $\begin{array}{l}.27^{* * *} \\
.17^{* * *} \\
.06^{*}\end{array}$ \\
\hline BIS: Total & $\begin{array}{l}\text { Step } 1 \\
\text { Step } 2 \\
\text { Step } 3\end{array}$ & $\begin{array}{l}\text { Group } \\
\text { Premature saccades } \\
\text { Group* } \\
\text { Premature saccades }\end{array}$ & $\begin{array}{l}1,56 \\
2,55 \\
3,54\end{array}$ & $\begin{array}{l}0.66 \\
0.34 \\
0.64\end{array}$ & $\begin{array}{l}0.10 \\
0.11 \\
0.59\end{array}$ & $\begin{array}{l}.44^{* * *} \\
.09^{* *} \\
.01\end{array}$ \\
\hline BIS: Attention & $\begin{array}{l}\text { Step } 1 \\
\text { Step } 2 \\
\text { Step } 3\end{array}$ & $\begin{array}{l}\text { Group } \\
\text { Premature saccades } \\
\text { Group* } \\
\text { Premature saccades }\end{array}$ & $\begin{array}{l}1,56 \\
2,55 \\
3,54\end{array}$ & $\begin{array}{l}0.70 \\
0.13 \\
0.28\end{array}$ & $\begin{array}{l}0.10 \\
0.11 \\
0.61\end{array}$ & $\begin{array}{l}.48^{* * *} \\
.01 \\
.00\end{array}$ \\
\hline BIS: Motor & $\begin{array}{l}\text { Step } 1 \\
\text { Step } 2 \\
\text { Step } 3\end{array}$ & $\begin{array}{l}\text { Group } \\
\text { Premature saccades } \\
\text { Group* } \\
\text { Premature saccades }\end{array}$ & $\begin{array}{l}1,56 \\
2,55 \\
3,54\end{array}$ & $\begin{array}{l}0.58 \\
0.32 \\
0.63\end{array}$ & $\begin{array}{l}0.11 \\
0.12 \\
0.66\end{array}$ & $\begin{array}{l}.33^{* * *} \\
.08^{* *} \\
.01\end{array}$ \\
\hline $\begin{array}{l}\text { BIS: } \\
\text { Non-Planning }\end{array}$ & $\begin{array}{l}\text { Step } 1 \\
\text { Step } 2 \\
\text { Step } 3\end{array}$ & $\begin{array}{l}\text { Group } \\
\text { Premature saccades } \\
\text { Group* } \\
\text { Premature saccades }\end{array}$ & $\begin{array}{l}1,56 \\
2,55 \\
3,54\end{array}$ & $\begin{array}{l}0.49 \\
0.05 \\
0.75\end{array}$ & $\begin{array}{l}0.12 \\
0.12 \\
0.68\end{array}$ & $\begin{array}{l}.24^{* * * *} \\
.13^{* * *} \\
.01\end{array}$ \\
\hline $\begin{array}{l}\text { UPPS: } \\
\text { Premeditation }\end{array}$ & $\begin{array}{l}\text { Step } 1 \\
\text { Step } 2 \\
\text { Step } 3\end{array}$ & $\begin{array}{l}\text { Group } \\
\text { Premature saccades } \\
\text { Group* } \\
\text { Premature saccades }\end{array}$ & $\begin{array}{l}1,56 \\
2,55 \\
3,54\end{array}$ & $\begin{array}{l}0.39 \\
0.45 \\
1.39\end{array}$ & $\begin{array}{l}0.12 \\
0.28 \\
0.70\end{array}$ & $\begin{array}{l}.15^{* *} \\
.15^{* * *} \\
.05^{*}\end{array}$ \\
\hline UPPS: Urgency & $\begin{array}{l}\text { Step } 1 \\
\text { Step } 2 \\
\text { Step } 3\end{array}$ & $\begin{array}{l}\text { Group } \\
\text { Premature saccades } \\
\text { Group* } \\
\text { Premature saccades }\end{array}$ & $\begin{array}{l}1,56 \\
2,55 \\
3,54\end{array}$ & $\begin{array}{l}0.40 \\
0.13 \\
0.60\end{array}$ & $\begin{array}{l}0.12 \\
0.14 \\
0.79\end{array}$ & $\begin{array}{l}.16^{* *} \\
.01 \\
.01\end{array}$ \\
\hline UPPS: SS & $\begin{array}{l}\text { Step } 1 \\
\text { Step } 2 \\
\text { Step } 3\end{array}$ & $\begin{array}{l}\text { Group } \\
\text { Premature saccades } \\
\text { Group* } \\
\text { Premature saccades }\end{array}$ & $\begin{array}{l}1,56 \\
2,55 \\
3,54\end{array}$ & $\begin{array}{l}0.13 \\
0.32 \\
-0.42\end{array}$ & $\begin{array}{l}0.13 \\
0.15 \\
0.08\end{array}$ & $\begin{array}{l}.02 \\
.08^{*} \\
.00\end{array}$ \\
\hline $\begin{array}{l}\text { UPPS: } \\
\text { Perseverance }\end{array}$ & $\begin{array}{l}\text { Step } 1 \\
\text { Step } 2 \\
\text { Step } 3\end{array}$ & $\begin{array}{l}\text { Group } \\
\text { Premature saccades } \\
\text { Group* } \\
\text { Premature saccades }\end{array}$ & $\begin{array}{l}1,56 \\
2,55 \\
3,54\end{array}$ & $\begin{array}{l}0.58 \\
0.10 \\
1.27\end{array}$ & $\begin{array}{l}0.11 \\
0.13 \\
0.68\end{array}$ & $\begin{array}{l}.34^{* * *} \\
.01^{* * * * *} \\
.04^{* * *}\end{array}$ \\
\hline $\begin{array}{rl}* & p<.05 . \\
* * & p<.01 . \\
* * * & p<.001 . \\
* * * * & p=.07 .\end{array}$ & & & & & & \\
\hline
\end{tabular}

without ADHD. The major aim of this study was to determine whether the relation between inhibitory control and impulsivity differed according to the type of inhibitory control being assessed. Both a visual stopping task and a DORT assessed oculomotor inhibitory control

Table 4

Correlations among self-reported impulsivity measures and behavioral inhibitory control tasks.

\begin{tabular}{|c|c|c|c|c|c|c|c|c|}
\hline & Prem & VSSRT & MSSRT & P-Fail & Prem & VSSRT & MSSRT & P-Fail \\
\hline & \multicolumn{4}{|c|}{ Control group } & \multicolumn{4}{|c|}{ ADHD group } \\
\hline \multicolumn{9}{|l|}{ Self-report } \\
\hline I7 & -.09 & .03 & -.19 & -.14 & $.72^{* * *}$ & .37 & .04 & .18 \\
\hline BIS: Total & .07 & .11 & -.15 & -.11 & $.53^{* *}$ & $.51^{* *}$ & .16 & $.36^{*}$ \\
\hline BIS: Attention & .02 & .26 & -.23 & -.05 & .25 & $.45^{*}$ & .25 & $.43^{*}$ \\
\hline BIS: Motor & .05 & .18 & .14 & -.09 & $.46^{*}$ & $.57^{* *}$ & .27 & .11 \\
\hline BIS: NP & .08 & -.10 & -.21 & -.11 & $.57^{* *}$ & .27 & -.03 & $.38^{*}$ \\
\hline UPPS: Premed & -.05 & -.08 & -.08 & -.12 & $.64^{* * *}$ & .22 & -.12 & .09 \\
\hline UPPS: Urge & -.01 & .03 & -.05 & -.17 & .19 & $.41^{*}$ & .25 & .06 \\
\hline UPPS: SS & .26 & .27 & .17 & .16 & .32 & .30 & .10 & .17 \\
\hline UPPS: Persev & -.23 & -.21 & -.22 & -.28 & .32 & .10 & .12 & .34 \\
\hline \multicolumn{9}{|l|}{ Behavioral } \\
\hline Prem & 1.00 & .29 & .22 & -.09 & 1.00 & $.45^{*}$ & .02 & .31 \\
\hline VSSRT & & 1.00 & $.64^{* * *}$ & .11 & & 1.00 & $.53^{*}$ & -.02 \\
\hline MSSRT & & & 1.00 & -.11 & & & 1.00 & -.10 \\
\hline P-Fail & & & & 1.00 & & & & 1.00 \\
\hline
\end{tabular}

Note: Prem refers to premature saccades on the delayed ocular response task. VSSRT and MSSRT refer to visual and manual stop signal reaction times, respectively. P-fail refers to proportion of inhibitory failures during go cue/no-go target trials. For control group, $d f=26$. For ADHD group, $d f=28$. For correlations including SSRT on the visual stopping task in the ADHD group, $d f=26$.

$$
\begin{array}{rl}
* & p<.05 . \\
* * & p<.01 . \\
* * * & p<.001 .
\end{array}
$$


by assessing participants' ability to inhibit a saccadic eye movement. A manual stopping task and a cued go/no go task were used to measure manual inhibitory control by assessing participants' ability to inhibit a manual response. The results revealed that visual SSRT was a stronger predictor of impulsivity than manual SSRT. This finding supports the notion that oculomotor inhibitory control is uniquely related to impulsivity. In addition, we sought to examine how the relation between behavioral and self-report measures differed between disinhibited and normal populations. The relations between oculomotor inhibitory control and several facets of impulsivity were most evident in those with ADHD and not controls. This suggests that oculomotor inhibitory control plays a role in the symptoms of impulsivity associated with ADHD.

The results of this study were supportive of our hypothesis that oculomotor inhibitory control tasks would be more closely related to self-reported impulsivity than manual inhibitory control. This is consistent with prior literature that has demonstrated this pattern of associations (Jacob et al., 2010). Reasons why oculomotor inhibition showed a stronger relation to impulsivity are not entirely clear. It may be that oculomotor inhibitory control systems subserve general impulse control to a greater degree than manual inhibitory control. Indeed, oculomotor inhibition is critical for fundamental functions, such as the control and selection of attention to relevant stimuli and to the ability to effectively ignore irrelevant, distracting stimuli (Houghton \& Tipper, 1994). Norman and Shallice (2000) reviewed experimental evidence implicating the control of attentional resources in action execution; these authors noted the importance of effective attentional control in tasks that "require the overcoming of a strong habitual response or resisting temptation" (p. 377). In the cognitive sciences, the premotor theory of attention posits a close link between attention allocation and saccadic eye movements, and experimental evidence has demonstrated a degree of interdependence between attention and manual response processes (Eimer, Forster, Van Velzen, \& Prabhu, 2005). Considering this, it is possible that disrupted inhibitory control of attention manifests as impulsivity.

Alternatively, the finding that oculomotor inhibitory control is more closely related to impulsivity than manual inhibitory control may relate to task characteristics. In addition to differences in response modality (i.e., ocular versus manual), these tasks differ in the type of response prepotency. Specifically, the oculomotor inhibitory control tasks require the inhibition of a reflexive response, whereas the to-be-inhibited response in the manual task is not reflexive in nature (Logan \& Irwin, 2000). The oculomotor inhibitory control tasks required participants to stymie a saccade towards a distracter stimulus. Visual orientation towards the abrupt presentation of a peripheral stimulus is an innate reflex that is present from early infancy (Johnson, 1995). Conversely, the manual inhibitory control tasks required the participant to inhibit a button press. Although steps can be taken to increase response prepotency (e.g., response cueing, manipulating stop-trial frequencies, manipulating stimulus-onset asynchronies), these responses are prepotent inasmuch as the participant complies with the task instructions. Perhaps the executive override of an innate reflex better approximates impulse control in a natural setting than the inhibition of an artificial task demand. This notion might be tested with a novel inhibitory control task that requires the executive override of a reflexive manual response.

In sum, it appears that inhibitory control of oculomotor functioning bears a closer relation to self-report indicators of impulsivity than does inhibitory control of manual responses. However, it is important to recognize that despite this evidence for independence, the present study also demonstrated significant correlations between performance on the visual and manual stopping tasks that should be considered, as they demonstrate some degree of interdependence between the inhibitory control of manual and oculomotor responses.
There were also group differences in the degree to which measures of inhibitory control related to impulsivity. The tendency to display premature saccades on the DORT was more closely related to impulsivity in the ADHD group than the control group. This finding indicates that impairments of oculomotor inhibitory control are linked to impulsive behavior uniquely in adults with ADHD. This raises an important consideration for understanding the cognitive correlates of impulsivity in clinical populations. Even when appropriately decomposed into homogeneous personality constructs, there are likely to be multiple cognitive, behavioral, and affective factors that contribute to the traits measured by impulsivity inventories. Consider, for example, the basic psychological processes that are likely associated with lack of premeditation. One might speculate that effective planning requires the ability to hold a goal and various contingencies in working memory and inhibit responding until this information has been evaluated. Disruption in any of these cognitive processes may result in lack of premeditation.

Behavioral inhibitory control tasks, however, are designed to measure a relatively specific cognitive process (Dick et al., 2010). The relative contribution of individual cognitive processes to complex personality traits may differ in populations characterized by psychopathology. It is possible that lack of premeditation is driven by impaired oculomotor inhibitory control uniquely in adults with ADHD, but not in other groups characterized by this type of impulsivity. For example, impaired premeditation in substance dependent individuals may relate to working memory deficits or reward sensitivity. Alternatively, the reported interactions could be interpreted as a restricted range of DORT performance in the control group. In either case, further work is needed to better understand how cognitive correlates of impulsivity differ in clinical groups.

Members of the ADHD group showed larger impairment on the oculomotor stopping task relative to the manual stopping task. This finding further highlights the dissociation between oculomotor and manual inhibitory control. Furthermore, it appears that oculomotor inhibitory control measures better capture the inhibitory deficits experienced by adults with ADHD. This is consistent with Adams et al. (2010) who concluded that the oculomotor stopping task is more sensitive to the cognitive deficits observed in children with ADHD. In sum, adults with ADHD seem to have more difficulty inhibiting eye movements than manual movements, and this dysfunction in oculomotor inhibitory control relates to impulsivity-a core feature of the disorder. Taken together, these pieces of evidence suggest that oculomotor inhibitory control may be more important than manual inhibitory control in understanding the neurological profile and functional impairment of adults with ADHD.

It is also interesting that among the variables of the cued go/no-go task, only the proportion of inhibitory failures in go cue/no-go target trials failed to show differences between groups. Prior work has shown that inhibitory failures during go cue/no-go target trials are elevated under conditions of disinhibition (e.g., alcohol intoxication; Marczinski \& Fillmore, 2003), whereas inhibitory failures during nogo cue/no-go target trials are often unaffected by such conditions. These findings can most likely be explained in terms of a speed-accuracy tradeoff (Fillmore, 2007), because the ADHD group was slower to respond than the control group.

The findings of this study inform our understanding of the cognitive correlates of different facets of impulsivity. Most notable, premature saccades on the DORT correlated closely with scores on the UPPS: (lack of) Premeditation and the I7. These inventories similarly measure the lack of planning disposition discussed by Dick et al. (2010). This overlap was confirmed in our data, as these two measures were correlated similarly with behavioral tasks. Individuals who are low in premeditation have difficulty planning out actions and anticipating consequences, and tend to act on previously rewarded behavior without reflecting on changing contingencies (Whiteside \& Lynam, 2001). Based on our data, it seems that lack of premeditation 
also relates to individuals' ability to inhibit reflexive behaviors based on contingencies (i.e., task instructions). Interestingly, oculomotor inhibitory control was not related to lack of perseverance. Inhibiting attentional shifts towards distractions has straightforward application to persevering in undesirable tasks. That this relation did not emerge empirically suggests that susceptibility to distracting stimuli may not be a determinant of task perseverance; perhaps susceptibility to endogenous sources of distraction better accounts for this trait (e.g., mind wandering; Gay et al., 2011).

\subsection{Limitations}

The results of the current study contribute to our understanding of the relation between inhibitory control processes and impulsivity; however, there are some limitations. First, there were a large number of statistical tests conducted without corrections for inflated Type I error rate. As such, this research might be considered as preliminary and subject to replication. However, it is compelling that the pattern of findings were consistent across conceptually similar measures of impulsivity (i.e., I7, UPPS: [lack of] premeditation). Second, the use of a single ADHD group may have obscured differences between subtypes. It is possible that manual inhibitory control deficits are more central to the symptomatology of individuals with ADHD-combined type. Third, we limited participation to adults with ADHD who were currently taking prescription medication, and it may not be appropriate to generalize our findings to adults with ADHD who are not prescribed psychostimulant medication. Finally, there were several participants in the control group who scored in the positive range on one or more of the ADHD symptom self-report measures, and the inclusion of these participants may have attenuated betweengroup differences.

In sum, the present research provides new information supporting the distinction between manual and oculomotor inhibitory control processes. Researchers have recognized the complex nature of inhibitory control and the importance of decomposing the associated cognitive processes. Efforts have been made to identify which cognitive processes relate to impulsive traits; however, the distinction between manual and oculomotor inhibitory control has not been made in this context. By distinguishing between these types of inhibitory control the current study was able to show that oculomotor, but not manual, inhibitory control is related to specific facets of impulsive behavior. Furthermore, this study demonstrated the importance of considering clinical groups when examining the cognitive correlates of impulsivity.

\section{Acknowledgments}

This research was supported by the National Institute on Drug Abuse grants DA021027 and DA005312 and National Institute on Alcohol Abuse and Alcoholism grants AA012895 and AA018274.

\section{References}

Adams, Z. W., Milich, R., \& Fillmore, M. T. (2010). Examining manual and visual response inhibition among ADHD subtypes. Journal of Abnormal Child Psychology, 38, 971-983.

Adams, Z. W., Roberts, W., Fillmore, M. T., \& Milich, R. (2011). Does response variability predict distractibility among adults with attention-deficit/hyperactivity disorder? Psychological Assessment, 23, 427-436.

Alexander, G. E., Crutcher, M. D., \& DeLong, M. R. (1991). Basal ganglia-thalamocortical circuits: Parallel substrates for motor, oculomotor, "prefrontal" and "limbic" functions. Progress in Brain Research, 85, 119-145.

American Psychiatric Association (1994). Diagnostic and statistic manual of mental disorders (4th ed.). Washington, DC: Author.

Aron, A. R., Durston, S., Eagle, D. M., Logan, G. D., Stinear, C. M., \& Stuphorn, V. (2007). Coverging evidence for a fronto-basal-ganglia network for inhibitory control of action and cognition. The Journal of Neuroscience, 27, 11860-11864.

Aron, A. R., Robbins, T. W., \& Poldrack, R. A. (2004). Inhibition and the right inferior frontal cortex. Trends in Cognitive Science, 8, 170-177.
Chevrier, A. D., Noseworthy, M. D., \& Schachar, R. (2007). Dissociation of response inhibition and performance monitoring in the stop signal task using event-related fMRI. Human Brain Mapping, 28, 1347-1358.

Conners, C. K., Erhardt, D., \& Sparrow, E. P. (1999). Conners' Adult ADHD Rating Scales. Toronto, Canada: Multi-Health Systems.

Dick, D. M., Smith, G., Olausson, P., Mitchell, S. H., Leeman, R. F., O'Malley, S. S., et al. (2010). Understanding the construct of impulsivity and its relationship to alcohol use disorders. Addiction Biology, 15, 217-226.

Eimer, M., Forster, B., Van Velzen, J., \& Prabhu, G. (2005). Covert manual response preparation triggers attentional shifts: ERP evidence for the premotor theory of attention. Neuropsychologia, 43, 957-966.

Erhardt, D., Epstein, J. N., Conners, C. K., Parker, J. D. A., \& Sitarenios, G. (1999). Selfratings of ADHD symptoms in adults: II. Reliability, validity, and diagnostic sensitivity. Journal of Attention Disorders, 3, 153-158.

Everling, S., \& Fischer, B. (1998). The antisaccade: A review of basic research and clinical studies. Neuropsychologia, 36 885-599.

Eysenck, S. B. G., Pearson, P. R., Easting, G., \& Allsopp, J. F. (1985). Age norms for impulsiveness, venturesomeness, and empathy in adults. Personality and Individual Differences, 6, 613-619.

Fillmore, M. T. (2007). Acute alcohol-induced impairment of cognitive functions: Past and present findings. International Journal on Disability and Human Development, 6, 115-125.

Fillmore, M. T., Rush, C. R., \& Hays, L. (2006). Acute effects of cocaine in two models of inhibitory control: Implications of non-linear dose effects. Addiction, 101, 1323-1332.

Gay, P., Rochat, L., Billieux, J., d'Acremont, M., \& Van der Linden, M. (2008). Heterogeneous inhibition processes involved in different facets of self-reported impulsivity: Evidence from a community sample. Acta Psychologica, 129, 332-339.

Gay, P., Schmidt, R. E., \& Van der Linden, M. (2011). Impulsivity and intrusive thoughts: Related manifestations of self-control difficulties? Cognitive Therapy and Research, 35, 293-303. doi:10.1007/s10608-010-9317-z.

Godijn, R., \& Theeuwes, J. (2003). The relationship between exogenous and endogenous saccades and attention. In J. Hyona, R. Radach, \& H. Deubel (Eds.), The mind's eye: Cognitive and applied aspects of eye movement research (pp. 3-26). New York, NY: Elsevier.

Goldstein, M., Brendel, G., Tuescher, O., Pan, H., Epstein, J., Beutel, M., et al. (2007). Neural substrates of the interaction of emotional stimulus processing and motor inhibitory control: An emotional linguistic go/no-go fMRI study. Neurolmage, 36 1026-1040.

Hanes, D. P., \& Carpenter, R. H. S. (1999). Countermanding saccades in humans. Vision Research, 39, 2777-2791.

Hanes, D. P., Patternson, W. F., \& Schall, J. D. (1998). Role of frontal eye fields in countermanding saccades: Visual, movement, and fixation activity. Journal of Neurophysiology, 79, 817-834.

Houghton, G., \& Tipper, S. (1994). A model of inhibitory mechanisms in selective attention. In D. Dagenbach, \& T. H. Carr (Eds.), Inhibitory processes in attention, memory and language (pp. 53-112). New York: Academic Press.

Jacob, G., Gutz, L., Bader, K., Lieb, K., Tüscher, O., \& Stahl, C. (2010). Impulsivity in borderline personality disorder: Impairment in self-report measures, but not behavioral inhibition. Psychopathology, 43, 180-188.

Johnson, M. H. (1995). The inhibition of automatic saccades in early infancy. Developmental Psychobiology, 28, 281-291.

Kaufman, A. S., \& Kaufman, N. L. (1990). Kaufman Brief Intelligence Test. Circle Pines, MN: American Guidance Services, Inc.

Lane, S., Cherek, D., Rhoades, H. M., Pietras, C. J., \& Tcheremissine, O. V. (2003). Relationships among laboratory and psychometric measures of impulsivity: Implications in substance abuse and dependence. Addictive Disorders $\mathcal{E}$ Their Treatment, 2, 33-40.

Lawrence, A. J., Luty, J., Bogdan, N. A., Sahakian, B. J., \& Clark, L. (2009). Impulsivity and response inhibition in alcohol dependence and problem gambling. Psychopharmacology, 207, 163-172.

Logan, G. D. (1994). On the ability to inhibit thought and action. In D. Dagenbach, \& T. H. Carr (Eds.), Inhibitory processes in attention, memory, and language (pp. 189-239). Toronto: Academic.

Logan, G. D., Cowan, W. B., \& Davis, K. A. (1984). On the ability to inhibit simple and choice reaction time responses: A model and a method. Journal of Experimental Psychology: Human Perception and Performance, 10, 276-291.

Logan, G. D., \& Irwin, D. E. (2000). Don't look! Don't touch! Inhibitory control of eye and hand movements. Psychonomic Bulletin \& Review, 7, 107-112.

Logan, G. D., Schachar, R. J., \& Tannock, R. (1997). Impulsivity and inhibitory control. Psychological Science, 8, 60-64.

Macleod, C. M. (1991). Half a century of research on the Stroop effect: An integrative review. Psychological Bulletin, 109, 163-203.

Marczinski, C. A., \& Fillmore, M. T. (2003). Preresponse cues reduce the impairing effects of alcohol on the execution and suppression of responses. Experimental and Clinical Psychopharmacology, 11, 110-117.

Marzi, C. A. (1999). Neuropsychology of attention. In G. Denes, \& L. Pizzamiglio (Eds.), Handbook of clinical and experimental neuropsychology (pp. 509-524). Hove, East Sussex, England: Psychology Press.

Mitchell, S. H. (1999). Measures of impulsivity in cigarette smokers and non-smokers. Psychopharmacology, 146, 455-464.

Mostofsky, S. H., Schafer, J. G. B., Abrams, M. T., Goldberg, M. C., Flower, A. A., Boyce, A., et al. (2003). fMRI evidence that the neural basis of response inhibition is taskdependent. Cognitive Brain Research, 17, 419-430.

Nigg, J. T. (2000). On the inhibition/disinhibition in developmental psychopathology: Views from cognitive and personality psychology and a working inhibition taxonomy. Psychological Bulletin, 126, 220-246. 
Norman, D. A., \& Shallice, T. (2000). Attention to action: Willed and automatic control of behavior. In M. S. Gazzaniga (Ed.), Cognitive neuroscience: A reader. Maiden, MA: Blackwell.

Patton, J. H., Stanford, M. S., \& Barratt, E. S. (1995). Factor structure of the Barratt Impulsiveness Scale. Journal of Clinical Psychology, 51, 768-774.

Peterson, M. S., Kramer, A. F., \& Irwin, D. E. (2004). Covert shifts of attention precede involuntary eye movements. Perception \& Psychophysics, 66, 398-405.

Roberts, W., Fillmore, M. T., \& Milich, R. (2011). Separating automatic and intentiona inhibitory mechanisms of attention in adults with attention-deficit/hyperactivity disorder. Journal of Abnormal Psychology, 120, 223-233.

Robin, A. L., \& Vandermay, S. J. (1996). Validation of a measure for adolescent selfreport of attention deficit disorder symptoms. Developmental and Behavioral Pediatrics, 17, 211-215.

Rosenberg, D. R., Averbach, D. H., O'Hearn, K. M., Seymour, A. B., Birmaher, B., \& Sweeney, J. A. (1997). Oculomotor response inhibition abnormalities in pediatric obsessivecompulsive disorder. Archives of General Psychiatry, 54, 831-838.

Ross, R. G., Harris, J. G., Olincy, A., \& Radant, A. (2000). Eye movement task measure inhibition and spatial working memory in adults with schizophrenia, ADHD, and a normal comparison group. Psychiatry Research, 95, 35-42.
Rothbart, M. K., \& Ahadi, S. A. (1994). Temperament and the development of personality. Journal of Abnormal Psychology, 103, 55-66.

Schall, J. D., Stuphorn, V., \& Brown, J. W. (2002). Monitoring and control of action by the frontal lobes. Neuron, 36, 309-322.

Smith, G. T., \& Combs, J. (2010). Issues of construct validity in psychological diagnoses. In T. Millon, R. F. Krueger, \& E. Simonsen (Eds.), Contemporary directions in psychopathology: Toward the DSM-V and ICD-11. New York: Guilford Press.

Weafer, J., Fillmore, M. T., \& Milich, R. (2009). Increased sensitivity to the disinhibiting effects of alcohol in adults with ADHD. Experimental and Clinical Psychopharmacology, $17,113-121$.

Weafer, J., Fillmore, M. T., \& Milich, R. (2011). Behavioral components of impulsivity predict alcohol consumption in adults with ADHD and healthy controls. Drug and Alcohol Dependence, 113, 139-146.

Whiteside, S. P., \& Lynam, D. R. (2001). The five factor model and impulsivity: Using a structural model of personality to understand impulsivity. Personality and Individual Differences, 30, 669-689.

Young, S. (2004). The YAQ-S and YAQ-I: The development of self and informant questionnaires reporting on current adult ADHD symptomatology, comorbid and associated problems. Personality and Individual Differences, 36, 1211-1222. 